\title{
HARTWEG, Frédéric, HEIS, Joachim, DOHLE, Horst, SED und Kirche. Eine Dokumentation ihrer Beziehungen
}

Loïc Batel

\section{OpenEdition}

\section{Journals}

Édition électronique

URL : http://journals.openedition.org/ifha/1571

DOI : 10.4000/ifha.1571

ISSN : 2198-8943

Éditeur

IFRA - Institut franco-allemand (sciences historiques et sociales)

Référence électronique

Loïc Batel, «HARTWEG, Frédéric, HEIS, Joachim, DOHLE, Horst, SED und Kirche. Eine Dokumentation ihrer Beziehungen », Revue de l'IFHA [En ligne], Date de recension, mis en ligne le 01 janvier 1996, consulté le 22 septembre 2020. URL : http://journals.openedition.org/ifha/1571 ; DOI : https://doi.org/ 10.4000/ifha. 1571

Ce document a été généré automatiquement le 22 septembre 2020.

(C)IFHA 


\title{
HARTWEG, Frédéric, HEIS, Joachim, DOHLE, Horst, SED und Kirche. Eine Dokumentation ihrer Beziehungen
}

\author{
Loïc Batel
}

1 D'entrée les deux recueils de texte s'inscrivent dans une continuité et se présentent comme le second élément du triptyque consacré par les éditions Neukirchener aux relations de l'Église et de l'État en R.D.A. et entamé avec "Pfarrer, Christen, Katholiken«. Das Ministerium für Staatssicherheit der ehemaligen DDR und die Kirchen, paru sous la direction de BESIER et WOLF. Après ce premier volet offrant au lecteur/chercheur un choix de textes tirés des archives de la police d'état et destiné à rendre compte des rapports entretenus entre la Stasi et les Églises, qu'il s'agisse de leur surveillance, des pressions exercées sur elles ou le cas échéant de leur collaboration, les deux tomes ici présentés devraient en effet précéder à leur tour la parution prévue pour l'été 1996 d'un dernier élément sur le même thème constitué cette fois d'archives ecclésiastiques.

2 Les ouvrages, en présentant une série de documents du SED touchant à la politique ecclésiastique - respectivement 97 pour le premier tome, 120 pour le second et consistant en lettres, protocoles, rapports, exposés... - entendent permettre une »vue de l'intérieur«, selon le mot de l'introduction. Pour ce faire les auteurs ont choisi un découpage résolument chronologique, chacun des sept chapitres des deux tomes se voyant consacré à une période donnée en offrant chaque fois la même structure: une introduction substantielle comportant jusqu'à une soixantaine de pages où les documents présentés sont replacés dans un contexte lui aussi largement commenté, suivie des textes eux-mêmes.

3 Produire un recueil de textes sur un sujet aussi vaste et au milieu d'une documentation aussi exceptionnellement abondante implique bien évidemment des choix très sélectifs qui peuvent apparaître comme autant de sacrifices voire de lacunes par défaut. On peut néanmoins affirmer que les auteurs ont su éviter ce dernier écueil non seulement par un choix souvent judicieux - même s'il faut, dans les relations de l'Église et de l'État est- 
allemand souvent se garder du souci de "représentativité» - et surtout en accompagnant ces sources d'un appareil critique conséquent: au-delà des introductions précédant chaque série de documents dont il faut redire la richesse, on citera encore les chronologies détaillées ou les notices biographiques fort utiles présentées en fin d'ouvrage. Seul regret peut-être, une présentation du contexte qui privilégie avant tout la politique intérieure de la R.D.A. et les arcanes du pouvoir au sein du S.E.D sans toujours prendre assez en compte le contexte international, pourtant un des moteurs essentiels de l'action du régime.

LoÏc BATEL 